\title{
Paclitaxel-Loaded Polymeric Micelle
}

National Cancer Institute

\section{Source}

National Cancer Institute. Paclitaxel-Loaded Polymeric Micelle. NCI Thesaurus. Code C48415.

A biodeg radable poly(ethylene glycol)-poly(D,L-lactide) copolymer micelle nanoparticleentrapped formulation of paclitaxel with antineoplastic activity. Paclitaxel promotes microtubule assembly and prevents depolymerization, thus interfering with normal mitosis. The copolymer residue increases the water-solubility of paclitaxel and allows delivery of higher doses than those achievable with paclitaxel alone. 